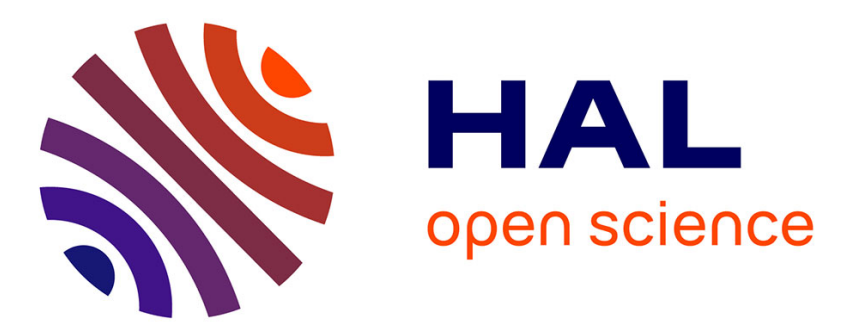

\title{
Precise motion control of a piezoelectric microgripper for microspectrometer assembly.
}

Kanty Rabenorosoa, Aditya N. Das, Rakesh Murthy, Cédric Clévy, Dan Popa, Philippe Lutz

\section{- To cite this version:}

Kanty Rabenorosoa, Aditya N. Das, Rakesh Murthy, Cédric Clévy, Dan Popa, et al.. Precise motion control of a piezoelectric microgripper for microspectrometer assembly.. ASME'09 International Design Engineering Technical Conferences (IDETC'09) \& Computers and Information in Engineering Conference (CIE'09)., Aug 2009, San Diego, CA., United States. 8 p. hal-00417722

\author{
HAL Id: hal-00417722 \\ https://hal.science/hal-00417722
}

Submitted on 17 Sep 2009

HAL is a multi-disciplinary open access archive for the deposit and dissemination of scientific research documents, whether they are published or not. The documents may come from teaching and research institutions in France or abroad, or from public or private research centers.
L'archive ouverte pluridisciplinaire HAL, est destinée au dépôt et à la diffusion de documents scientifiques de niveau recherche, publiés ou non, émanant des établissements d'enseignement et de recherche français ou étrangers, des laboratoires publics ou privés. 


\title{
Precise motion control of a piezolelectric microgripper for microspectrometer assembly
}

\author{
Kanty Rabenorosoa, Aditya N. Das*, Rakesh Murthy*, Cédric Clévy, Dan Popa* and Philippe Lutz \\ FEMTO-ST Inst., UMR CNRS 6174 - UFC / ENSMM / UTBM \\ and *Automation and Robotics Research Institute (ARRI) \\ Automatic Control and Micro-Mechatronic Systems depart.(AS2M department), \\ and *University of Texas at Arlington \\ 25000 Besancon and *Fort Worth \\ France and *Texas 76118 - USA \\ Email: rkanty, cclevy, plutz@femto-st.fr and *aditya ,rakesh, popa @arri.uta.edu
}

\begin{abstract}
The Fourier Transform (FTIR) microspectrometer discussed in this paper is an example of a complex Micro-OptoElectro-Mechanical System (MOEMS) configured as an optical bench on a chip. It is an important benchmark application for microtechnology due to increased demands for the use of miniature wavelength detection instruments in bio, nano and material science. This device can be manufactured using automated microassembly and precision alignment of hybrid silicon and glass components, and in particular, of a microbeamsplitter cube along 3 rotational degrees of freedom. In this paper, a piezoelectric microgripper with four degrees of freedom was attached to a precision robot in order to enhance its dexterity and align the beamsplitter to arcsecond angular tolerance. The modeling and control of the microgripper, and the alignment algorithm utilizing a novel spot-Jacobian servoing technique are discussed. Experimental results obtained during joint on-going work in Texas and in France are presented, demonstrating the advantage of using the microgripper for optical alignment of the microspectrometer.
\end{abstract}

\section{INTRODUCTION}

The miniaturization of many systems and products is today a pressing industrial need, and such endeavors constantly increase the precision demands achievable with commercially available robots. As a result, new scientific challenges in smallscale engineering, most notably in the micromanufacturing and microassembly fields must be addressed. The hybrid assembly of micrometric-size components, fabricated by a dedicated and, perhaps different processes, is a very promising new approach for incorporating increased functionalities into microsystems, such as miniaturized measurement instruments and microrobots.

Among such assembled devices, micro-optical systems (fiber coupling, microspectrometers, microscanners, etc.) are both challenging and offer a wide application domain. Macrooptical systems generally combine mixed materials such as optical glass, polymers, and semiconductor materials. Given well-known limitations in monolithic microfabrication technologies (cost, yield, process incompatibility, etc.), assembly offers an attractive alternative, however, it adds additional complexities related to precision manipulation (gripping, assembly, positioning), as well as packaging (bonding, sealing, etc.), thus requiring new paradigms in automation and robotics at small-scales. An example of a hybrid assembled micro-

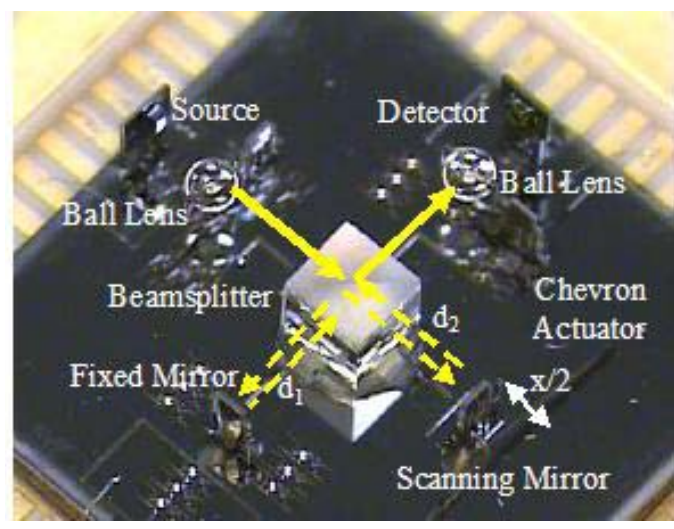

Fig. 1. HYBRID MICROSPECTROMETER ASSEMBLED AT ARRI.

optical system is the microspectrometer recently constructed at UT Arlington's Texas Microfactory [1], (see. Fig. 1). This device implements a Michelson interferometer on a Silicon die by precision assembly of sub- $\mu \mathrm{m}$ silicon and glass MEMS parts, and their alignment to tolerances of a few microns and arcseconds.

Despite recent advances in microassembly, much work remains to be done in micromanipulation and assembly for highyield and high-throughput automation [2]. Among remaining challenges are the nonlinear behavior of smart microactuators that require complex control algorithms in order to generate accurate and reliable motions, the integration of force and imaging sensors into very small workspaces, and the unpredictable behavior of manipulated microobjects due to increased adhesion forces at small-scales [3].

This paper proposes a new method to assemble the microspectrometer by using a piezoelectrically-driven microgripper, in order to precisely control the orientation of several light surfaces, such as mirrors and the center beamsplitter. In particular, the beamsplitter is the last assembled component, and requires full 6 degrees-of-freedom (DOF) micromanipulation 
with high accuracy ( 3 arcseconds of precision in all rotational DOF). In this paper, a microgripper developed by FEMTOST Institute in France was used to control the 3D pose of the beamsplitter and to achieve the stringent rotational dexterity and accuracy requirements for aligning the free-space microoptics. The paper is organized as follows: First, we briefly discuss the microspectrometer components, the kinematics of the microassembly station, and the assembly and alignment sequence for its construction. We then describe the working principle of the 4 DOF microgripper, and explain how the $3 \mathrm{D}$ rotation of the beam-splitter can be controlled. Section III details the hysteresis, creep and coupling compensation of the microgripper that is required to achieve precision motion control. Experimental results of beamsplitter servoing using a spot Jacobian mapping are included in section IV. Finally, section $\mathrm{V}$ concludes the paper and discusses future work.

\section{MiCRO-ASSEMBLY SYSTEM}

\section{A. Microspectrometer: Principle and Design}

The microspectrometer substrate consists of a $1 \mathrm{~cm} x 1$ $\mathrm{cm}$ silicon-on-insulator (SOI) die. Its design is based on a Michelson interferometer principle as depicted in figure 1 . On the substrate, we progressively assemble microcomponents including a monochrome visible light source, two MEMS mirrors for reflecting the light back to the device, two ball lenses for light collimation at the input and output, a beamsplitter for splitting the light along two paths and recombining it, and an optical detector.

In this section, we summarize the micro-components that require assembly and manipulation. The first component is a single-mode fiber with a $10 \mu \mathrm{m}$ core diameter to couple the light from an external fabry-perot $635 \mathrm{~nm}$ laser source. Prior to being injected into to the device, the light is collimated through a $800 \mu \mathrm{m}$ diameter sperical lens. A beamsplitter cube $1.3 \mathrm{~mm}$ in size splits the incident laser beam into two orthogonal halves and sends them onto the two Aucoated, vertically placed micromirrors. One half is reflected off a fixed MEMS mirror, with a reflective gold surface $1000 \mu \mathrm{m} \times 800 \mu \mathrm{m} \times 2 \mu \mathrm{m}$, at a distance of $4.5 \mathrm{~mm}$ from the beam splitter. The other half is reflected from a similar micromirror surface assembled on a MEMS electro-thermal Chevron actuator shuttle. By $45 \mu \mathrm{m}$ in-plane scanning motion of this mirror the optical light path difference between the half beams changes and interference fringes appear on the detector plane. Along with the micromirrors, two additional MEMS fixtures vertically hold the spherical ball lenses, and are fabricated from $100 \mu \mathrm{m}$ thick SOI using deep-reactive-ionetching (DRIE). Compliant snap-fastener joints are employed in order to assemble these components vertically to the device die. For additional joint strength reliability, epoxy glue was used to bond the microparts to the device die. After freespace propagation and repeated reflections, the laser beams will generate two spots on the detector plane. If all components are aligned to certain position tolerance thresholds, varying from 0.25 degrees for micromirrors, and 3 arcseconds $(0.8$ millidegrees) for beamsplitter, the $100 \mu \mathrm{m}$ laser spot locations on the detector plane will overlap by a sufficiently large area in order to generate interference fringes, which cycle between constructive or destructive, (bright or dark) fringe patterns while the actuator scans latterally. The interferogram signal obtained with a detector is recorded along with the corresponding displacement of the movable mirror. By taking the inverse Fourier transformation of this interferogram data, the spectrum of the input light signal has been recovered and the input wavelength can be identified. In a typical detection application, by allowing the input light to pass through a unknown gas medium, the microspectrometer can recover the absorbed spectrum and thus identify the gas. [4] discusses design, tolerancing, and assembly aspects of the microspectrometer in more detail.

\section{B. Microassembly System and Assembly Sequence}

A high precision robotic assembly system called $\mu^{3}$ (fig. 2) located at ARRI's Texas Microfactory Institute has been used to align and assemble the microspectrometer. The $\mu^{3}$ consists of three robots M1, M2 and M3 with a total of 19 degrees of freedom and a workvolume of approximately 8 $\mathrm{cm}^{3}$. To handle parts of different size and shapes the $\mu^{3}$ is equipped with quick-mount end effectors, and in [4] a passive compliant microjammer was used to handle the micromirrors, while a vacuum microneedle was employed to adjust the pose of the beamsplitter and assemble the spherical ball lenses. The $\mu^{3}$ is also equiped with microscopes for stereo vision, and several other packaging tools (such as epoxy dispensing, vacuum source, UV curing lamp, etc.) More details about the $\mu^{3}$ system can be found in [1]. In the work described in this paper, we replaced the vacuum needle on manipulator M2 with a 4-DOF piezoelectric microgripper that provides increased dexterity for the manipulation of the beamsplitter cube and other microspectrometer components.

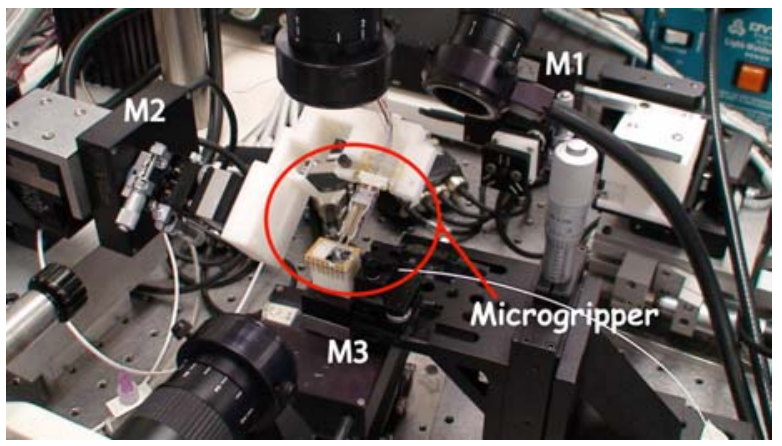

Fig. 2. $\mu^{3}$ MICROASSEMBLY SYSTEM AT ARRI'S MICRO FACTORY.

Based on the workspace constraints of the robots and optical precision requirements, the following semi-automated assembly strategy for the microspectrometer was employed:

1) Calibrating the robots in the workspace in order to obtain tolerable end-effector precision bounds. 
2) Using the passive microjammer, pick and place the ball lens holders using a 90 degree rotation through a terminating roll on manipulator M1.

3) Using the vacuum microneedle pick, manipulate and place the ball lenses onto compliant sockets on the lens holders.

4) Using the passive microjammer pick, manipulate and place the fixed mirror onto a compliant substrate socket.

5) Using the passive microjammer pick, manipulate and place the movable mirror onto a socket on the actuator shuttle.

6) Performing machine vision-assisted "coarse" alignment of the MEMS mirrors to nominal vertical directions.

7) Performing machine vision-assisted "coarse" alignment of the input fiber to the device such that incident light is collimated.

8) Using a 4DOF piezoelectric microgripper, pick up the beamsplitter cube and coarsely translate it to the center of microspectrometer.

9) Identifying the components of a Spot-Jacobian mapping relating the movement of the laser spots onto the detector plane to $3 \mathrm{D}$ rotational pose changes of the beamsplitter.

10) Performing automated "fine alignment" of the beamsplitter cube by sevoing the gripper arms until the two laser spots approach each other and overlap.

11) Finally, bonding the beamsplitter cube at the aligned position, and fix the detector at a location maximizing the signal-to-noise ratio (SNR).

In past work, [4], we servoed the micromanipulators M2 and M3 of the $\mu^{3}$ in 3DOF, in order to overlap the laser spots and create interference fringes. Since the rotational axes of the manipulators do not intersect at the center of the beamsplitter cube, it was also necessary to concurrently adjust the optical fiber position relative to the substrate. Because the beamsplitter pose adjustment requires arcsecond accuracy, it is highly advantageous if it can be accomplished by actuators located as close as possible to its local frame. In this paper, the addition of a microgripper with a local center of rotation greatly improves the dexterity required by the assembly operation, as discussed in Section IV.

\section{Working principle of the microgripper}

The microgripper comprises a pair of $4 \mathrm{DOF}$ piezoelectric actuator and 2 associated micromachined tool tips (see Fig. $3)$. The actuator is based on a duo-bimorph structure and is fabricated from PZT ceramic. Thanks to its kinematics, each of the microgripper fingers can move along $\mathrm{Y}$ or $\mathrm{Z}$ axis. Fig. 4 displays a cross-section of the actuator. Individual gripper fingers are powered through five electrodes (ground + four signals), and the combination of these signals enables coupled or decoupled motions. Fig. 5-a displays how we can obtain motion only along $\mathrm{Y}$ ( $\delta_{Y}$ of stroke). If the same voltage is applied to all four electrodes, then a motion along $\mathrm{Z}$ is obtained ( $\delta_{Z}$ of stroke, see Fig. 5-b). Finally the combination of these two output modalities also allows to obtain out of

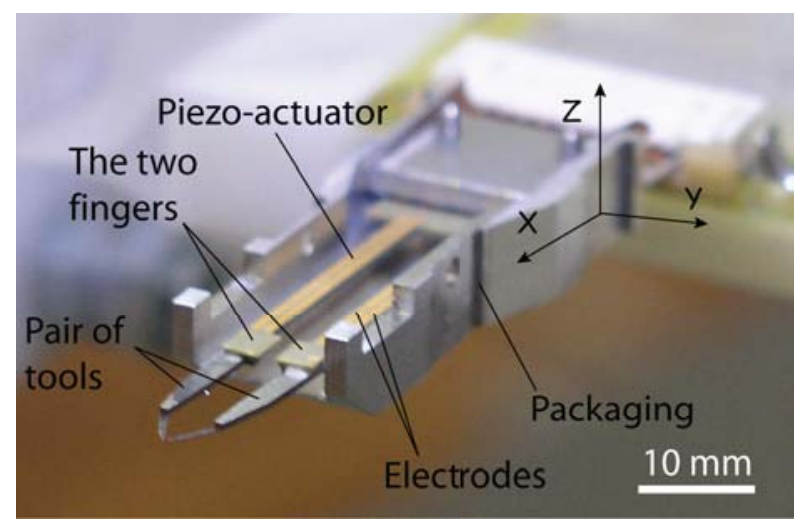

Fig. 3. STRUCTURE OF THE MICROGRIPPER [5].

plane motions (Fig. 5-c). More details about the actuator, the microgripper and its integration are available [6][7][8].

Because the gripper fingers are symmetric and can be driven independently, it is possible to drive both fingers in order to obtain a rotation of the object hold by the microgripper around the center gripper axis (see more details in section III-C). This roll motion is later exploited to pick-up, hold and align the beamsplitter. However, because the fingers are not identical, and their in-plane and out-of-plane motions are slightly coupled, accomplishing precision rotation motion requires a nonlinear compensation scheme, as detailed in section III.

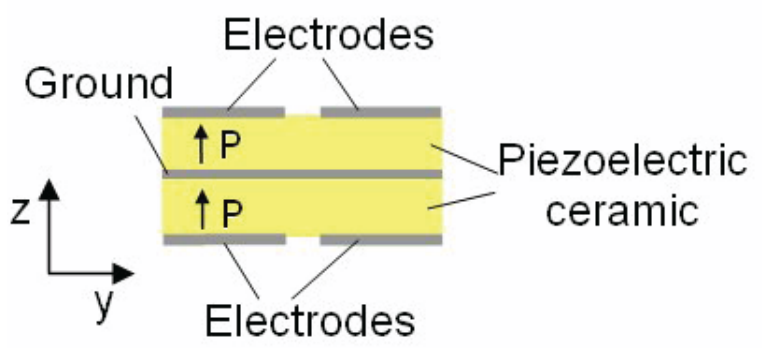

Fig. 4. CROSS SECTION OF THE PIEZOELECTRIC ACTUATOR.

\section{FINGER COUPLING COMPENSATION USING A NEURAL NETWORK}

Two kinds of tasks can be done with the microgripper:

- - Pick and place an object with dimension from few ten microns to a few mm

- - Fine rotation for accurate positioning.

For performing microspectrometer manipulation tasks, a precise control of the microgripper is needed. The attainable precision of PZT-driven smart actuators are often affected by coupling motion, hysteresis and creep [9], [10]. Coupling creates unwanted motions on one axis when the other one is actuated, complicating manipulation of microobject. Furthermore, hysteresis and creep influence the positioning repeatability and the accuracy of the microassembly system. 
(a)

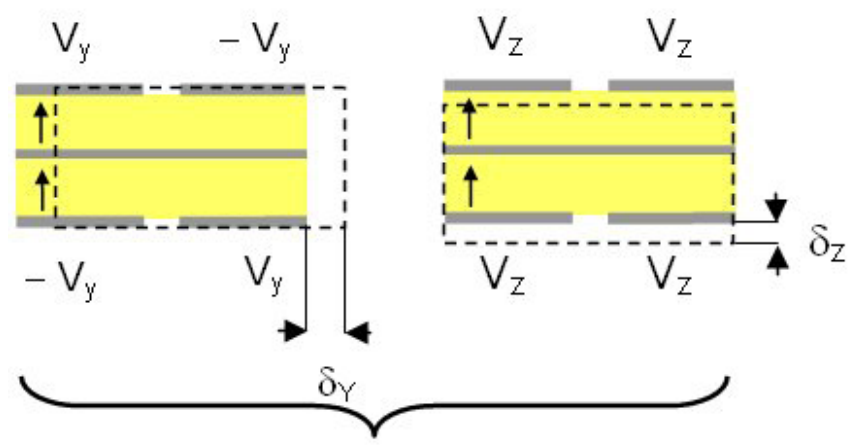

(c)

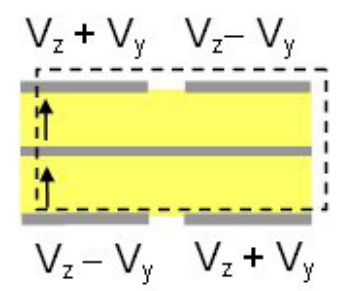

Fig. 5. CROSS SECTION OF 1 FINGER OF THE MICROGRIPPER. WORKING PRINCIPLE OF THE ACTUATOR: (A) MOTION ALONG Y (B) MOTION ALONG Z - (C) COMBINED MOTIONS ALONG Y AND Z.

For making displacement measurements of the microgripper, a specific experimental setup was used (see Fig. 6). Y and Z displacements were measured using a laser sensor (KEYENCE, LC $2400 \mathrm{~W}, 10 \mathrm{~nm}$ of resolution).

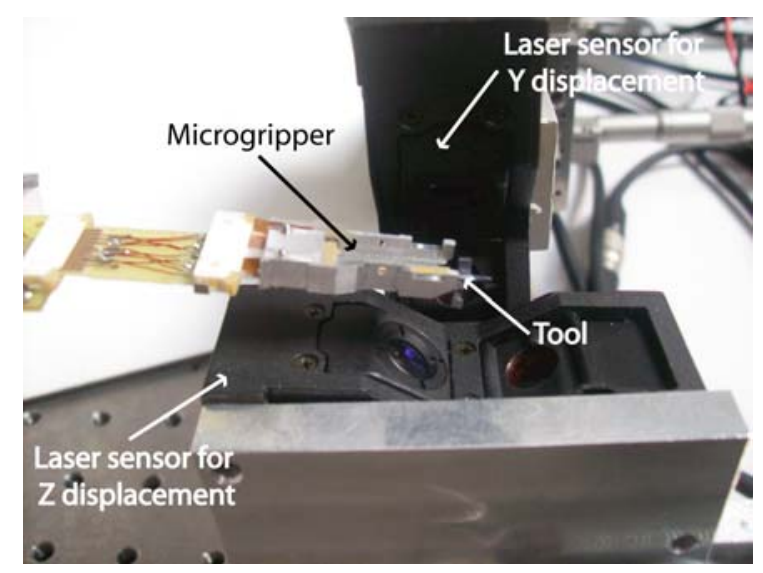

Fig. 6. SETUP FOR MEASURING Y AND Z DISPLACEMENT.

Measurements (see. Fig. 7) show that the hysteresis is around $6.8 \mu \mathrm{m}$ for $40 \mu \mathrm{m}$ displacement in $\mathrm{Y}(17 \%)$ and 18.55 $\mu \mathrm{m}$ for $125 \mu \mathrm{m}$ displacement in $\mathrm{Z}(14.8 \%)$. Coupling motion was around $19.53 \mu \mathrm{m}$ in $\mathrm{Y}$ for $\mathrm{Vz}$ actuation and negligible in $\mathrm{Z}$ for $\mathrm{Vy}$ actuation.

Active compensation of nonlinear behavior of the actuators can significantly improve the performance of the gripper for both teleoperated and automated modes. Before compensating the coupling motion, it is first necessary to reduce hysteresis effects. Indeed, coupling motion compensation is much easier
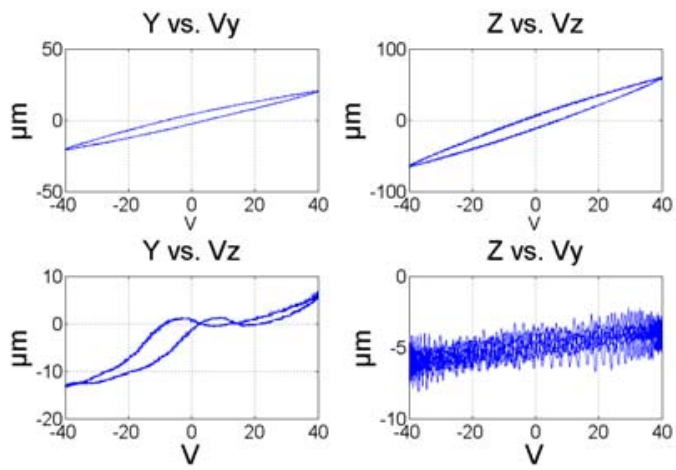

Fig. 7. ABOVE: MOTIONS ALONG Y - (A) (RESP. Z - (B)) FOR A VOLTAGE APPLIED TO OBTAIN A MOTION ALONG Y (REPS. Z) WITH HYSTERESIS OF PIEZOELECTRIC MICROGRIPPER WITH SINUSOIDAL ACTUATION (AMPLITUDE $=40$ VOLTS AND FREQUENCY $=0.4$ HZ). DOWN: COUPLED MOTION (MOTION OBTAIN ALONG Y - (C) FOR A VOLTAGE APPLIED TO OBTAIN A MOTION ALONG Z AND REVERSELY -(D)).

if model approximations do not include hysteretic behavior. Several methods to compensate creep have been developed in the past, for instance in [11] and [12].

\section{A. Hysteresis compensation}

The Prandtl-Ishlinskii (PI) static hysteresis model is used as introduced in [9]. This method is commonly appreciated for its simplicity of implementation, ease of obtaining the inverse analytical formulation and its efficiency. It is based on the superposition of many elementary backlash operators. After identification, modelling and compensation, the implementation is done with Simulink/dSPACE for $\mathrm{Y}$ and $\mathrm{Z}$ with $100 \mu$ s sampling time. This method is also named linearization according to the result obtained. The compensator is made with 25 hysterons (elementary backlash operators). More details about this method are available in [13].

Fig. 8 displays results of hysteresis compensation. Hysteresis effect is compensated and coupling motion in $\mathrm{Y}$ can be efficiently approximated by a neural network.
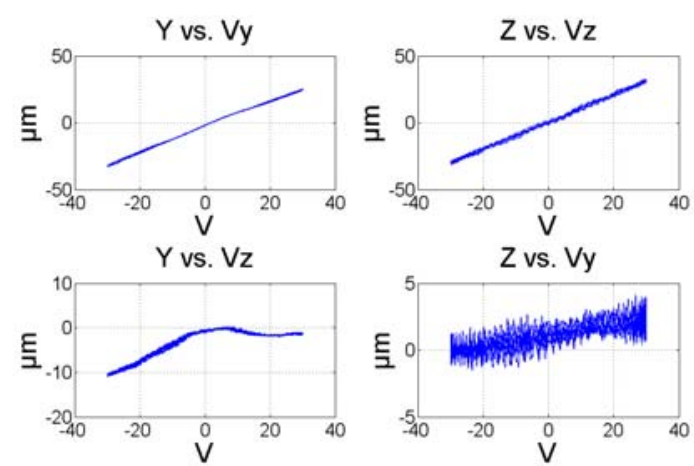

Fig. 8. MEASURES AFTER HYSTERESIS COMPENSATION. IN (A) (RESP. IN (B)), Y (RESP. Z) IS LINEAR ACCORDING TO THE APPLIED VOLTAGE. COUPLING MOTION OF $10 \mu \mathrm{M}$ IN Y IS SHOWN IN (C). 


\section{B. Coupling compensation}

The piezoelectric microgripper with the hysteresis compensator is considered as a new system. This new system is still affected by coupling motion in $\mathrm{Y}$ when $\mathrm{Vz}$ is actuated. Measurements (see. Fig. 8) show an unwanted motion of 10.9 $\mu \mathrm{m}$ in $\mathrm{Y}$ for $63.8 \mu \mathrm{m}$ in $\mathrm{Z}(16.7 \%)$.

For design static coupling compensation, neural networks are used. This solution is interesting because neural networks provide many interesting properties and capabilities. These include approximation or input-output mapping, complex nonlinear functions, and adaptivity [14], [15].

Compensator consists of two neural networks (Fig. 9 depicts the general principle and Fig. 10 the neural network architecture for coupling compensation). The first one approximate $\mathrm{Y}$ displacement according $\mathrm{Vz}$ actuation and the second one approximate the Vy actuation needed for Y displacement. Each network is constituted of tangsig function for first layer and linear function for the second layer. This type of neural network is able to make a universal approximation [16]. Levenberg-Marquardt algorithm is applied for training.

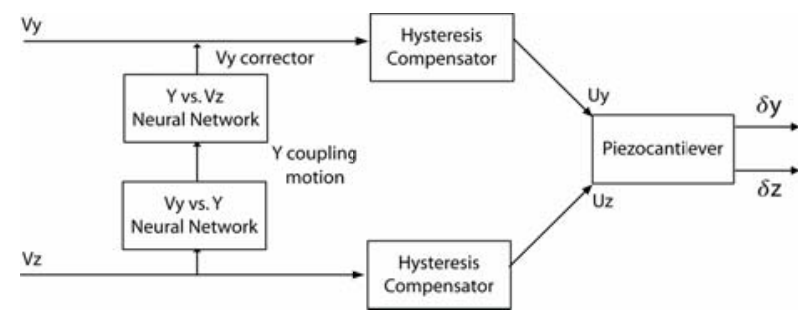

Fig. 9. BLOC DIAGRAM OF THE COMPENSATOR
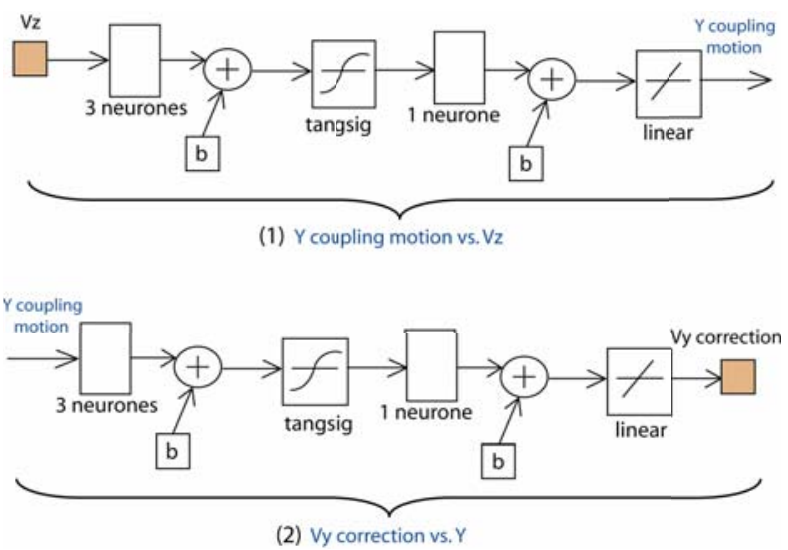

Fig. 10. NEURAL NETWORK ARCHITECTURE

After implementing neural networks in Simulink/MATLAB by using gensim command, a whole diagram of the corrected system is tested. Results show (see Fig. 11) that unwanted motion in $\mathrm{Y}$ when $\mathrm{Z}$ displacement is commanded is reduced to $2.4 \mu \mathrm{m}$ (10.9 $\mu \mathrm{m}$ before - 8-(c)- corresponding to a reduction of $78 \%)$.

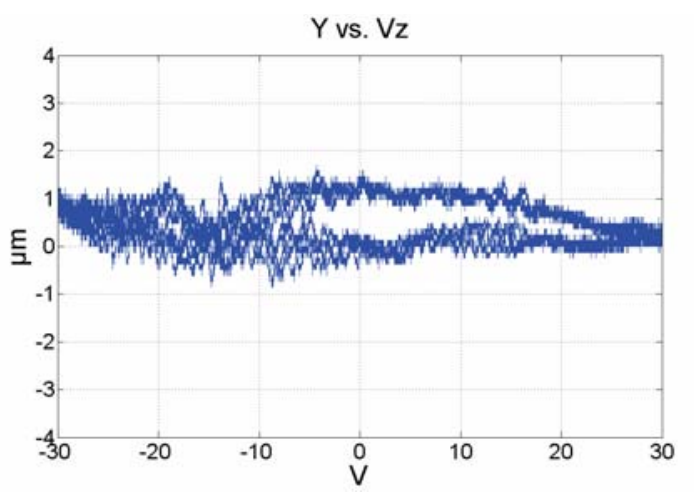

Fig. 11. MEASURE OF COUPLING MOTION WITH COMPENSATION

\section{Using microgripper for fine rotation}

After correcting the microgripper, fine rotation control of grasped part is programmed. It is possible when each finger of the microgripper is controlled to follow a circled trajectory. A model of plan contact between tools of microgripper and the object is calculated (see Fig: 12. It gives equations of applied voltages for each finger.

With $b=\sqrt{(a / 2)^{2}+(c / 2)^{2}}$, radius of trajectory

$\theta=$ angle, $d y 1=$ displacement in $\mathrm{Y}$ for Finger $1, d z 1=$ displacement in $\mathrm{Z}$ for Finger $1, d y 2=$ displacement in $\mathrm{Y}$ for Finger 2, and $d z 2=$ displacement in $\mathrm{Y}$ for Finger 2.

For finger 1:

$$
\left\{\begin{array}{r}
d y 1=-b(1-\cos \theta) \\
d z 1=b \sin \theta
\end{array}\right.
$$

For finger 2:

$$
\left\{\begin{array}{r}
d y 2=-b(1-\cos \theta) \\
d z 2=-b \sin \theta
\end{array}\right.
$$

The applied voltages $\mathrm{Vy} 1$ and $\mathrm{Vy} 2$ are equal, and the applied voltages in Vz1 and $\mathrm{Vz} 2$ are opposite. It is implemented in $\mathrm{PC}$ with $\mathrm{C}++$ and tested for rotating cubic part. Trajectory is observed by using pattern fixed on the manipulated object and vision recognition.

\section{Alignment of BEAMSPlitter FOR MICROSPECTROMETER}

The alignment of the beamsplitter pose requires 3 arcseconds of precision in all rotational degrees-of-freedom. This stringent tolerance suggests that the use of a well compensated microgripper is necessary to achieve the necessary motion accuracy. The relative position of the laser spots on the detector plane is related to the beamsplitter pose by a nonlinear transformation that can be obtained using a Spot Jacobian mapping. The Jacobian is a $2 \times 3$ matrix relating the three rotational velocities along roll, pitch and yaw to the relative velocities of the two spots. However, the RPY motions are coupled (e.g. 3 inputs, 2 outputs). The pitch and roll rotations around $\mathrm{Y}$ and $\mathrm{X}$ axes, repectively, both cause the spots to move 


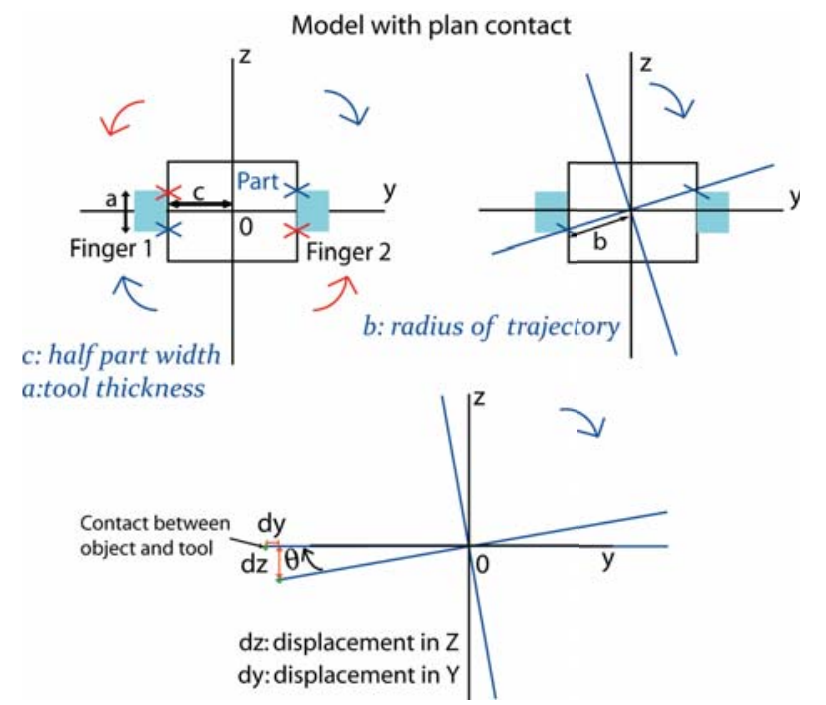

Fig. 12. FRONT SCHEME OF A PART HELD BY THE MICROGRIPPER ROTATION DESCRIPTION CONSIDERING PLAN CONTACT BETWEEN THE OBJECT AND TOOLS.

vertically on the rotation plane, while the Yaw rotation around $\mathrm{Z}$ causes the spots to move horizontally (see fig. 13). This suggests that a composite rotation with equal angles around both $\mathrm{Z}$ and $\mathrm{X}$ will cause the spots to move diagnonally until they overlap.

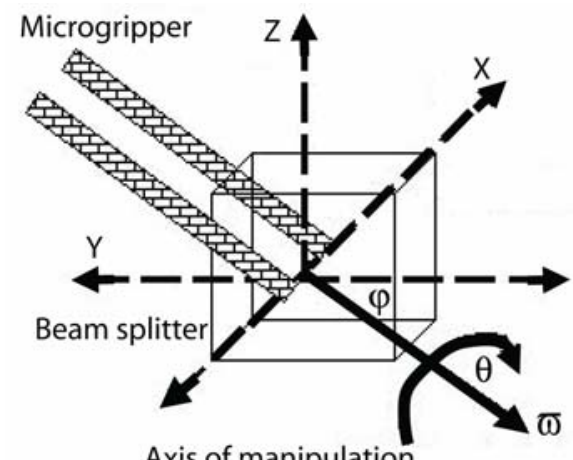

Fig. 13. COORDINATE SYSTEM OF MICROGRIPPER HOLDING THE BEAMSPLITTER AT ANGLE $\varphi$ ALONG PRINCIPAL AXIS $\bar{\omega}$.

In [4] the pose increments of the beamsplitter were obtained directly from the M2 robot, by measurements of axis encoders, while the spot positions were measured via image processing. We collected numerous calibration data points by moving the beamsplitter into different poses following a cubic grid. Using the data collected we identified the components of the Spot Jacobian. The spot Jacobian matrix provides a method to automate servoing on the beamsplitter poses in order to perform the alignment. Fine alignment was accomplished with exponential convergence by moving the beamsplitter according to a pseudo-inverse mapping between the spot position and the rotation angles.

In this paper, in order to servo the beamsplitter, the PZT microgripper was mounted on $\mu^{3}$ manipulator $\mathrm{M} 2$, in an orientation at a $45^{\circ}$ angle to the substrate as depicted in the diagram of figure 2. Rotations along the center axis of the microgripper will correspond to a screw motion along $\omega$ by an angle $\theta$, where

$$
\bar{\omega}=\left[\begin{array}{lll}
\cos \varphi & 0 & -\sin \varphi
\end{array}\right]^{T} .
$$

The corresponding rotation can be calculated from using Rodriguez's formula [17]:

$$
\begin{gathered}
R=e^{\hat{\omega} \theta}=\left.\left[r_{i j}\right]\right|_{1 \leq i \leq 3,1 \leq j \leq 3} \\
{\left[\begin{array}{ccc}
1-\sin ^{2} \varphi(1-\cos \theta) & \sin \varphi \sin \theta & -\sin \varphi \cos \varphi(1-\cos \theta) \\
-\sin \varphi \sin \theta & \cos \theta & -\cos \varphi \sin \theta \\
-\sin \varphi \cos \varphi(1-\cos \theta) & \cos \varphi \sin \theta & 1-\cos ^{2} \varphi(1-\cos \theta)
\end{array}\right] .}
\end{gathered}
$$

If $\phi=45^{\circ}$, from the above equation we find that $r_{11}=r_{33}$ and $r_{21}=-r_{32}$. In standard RPY notation the rotation matrix $R$ is given by:

$$
R=\left[\begin{array}{ccc}
c \alpha c \beta & c \alpha s \beta \sin \gamma-s \alpha c \gamma & c \alpha s \beta c \gamma+s \alpha s \gamma \\
s \alpha c \beta & s \alpha s \beta s \gamma+c \alpha c \gamma & s \alpha s \beta c \gamma-c \alpha s \gamma \\
-s \beta & c \beta s \gamma & c \beta c \gamma
\end{array}\right],
$$

where $\alpha, \beta, \gamma$ are the roll, pitch and yaw angles respectively. As a result, for $\phi=45^{\circ}$,

$$
[\cos \alpha=\cos \gamma, \sin \alpha=-\sin \gamma] \Rightarrow \alpha=-\gamma
$$

Thus if $\phi=45^{\circ}$ the corresponding pitch and yaw angles (e.g. rotations along $\mathrm{Z}$ and $\mathrm{Y}$ axes) will be equal and oposite to each other. This means that by implementing a screw motion with the two microgripper fingers around the center axis at a $45^{\circ}$ angle to the substrate, we can obtain a composite rotation that directly reduces the laser spot separation. This approach greatly amplifies the manipulation sequence and expedites the alignment process to the required accuracy.

Thus, the microgripper's 4 degrees of freedom are utilized as follows: the lateral finger motion is used to grasp the sides of the beamspliter cube, while the finger trajectory is used during alignment of the laser spots. Fig. 14 shows successive positions of the laser spots during the manipulation sequence that lead to a successful spot overlap.

(1)

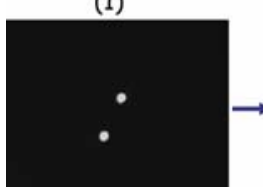

Fig. 14. SUCCESSIVE POSITIONS OF LASER SPOTS DURING MANIPULATION.

\section{CONCLUSION}

In this paper we employ a 4 DOF microgripper to increase the dexterity and precision necessary to align a microoptical component, a beamsplitter cube, and obtain interference fringes for a FTIR microspectrometer. We use an 
neural network to decouple the gripper finger motions, and compensate for nonlinearities. An improvement of $78 \%$ of the coupling is obtained after correcting hysteresis effect. This allows the precise control of finger motions with high accuracy. Due to the special grasping pose at a 45 degree angle from the substrate, we accomplished the necessary alignment trajectory for the beamsplitter pose with only one composite rotation. The addition of local rotational degrees of freedom close to the microobject is a much better choice for the stringent accuracy required by this operation. Future work will include full automation of microassembly process on the $\mu^{3}$ system, assembly planning, and the use of the microgripper for manipulation of other micro-optical components.

\section{ACKNOWLEDGMENT}

This work was supported in part by the US Office of Naval Research under grant N00014-06-1-1150, and the EU MIAAMI project (Région Franche-Comté). We would also like to acknowledge the support of Rémi Braud for his experimental help at ARRI, Jeongsik Sin for the design of the microspectrometer, and Micky Rakotondrabe for discussions about hysteresis compensation.

\section{REFERENCES}

[1] A. Das, P. Zhang, W. Lee, D. Popa, and H. Stephanou, “ $\mu^{3}$ : Multiscale, deterministic micro-nano assembly system for construction of on-wafer microrobots," in IEEE International Conference on Robotics and Automation, Roma, Italy, April 2007, pp. 461 - 466.

[2] H. V. Brussel, J. Peirs, D. Reynaerts, A. Delchambre, G. Reinhart, N. Roth, M. Weck, and E. Zussman, "Assembly of microsystems," Annals of the CIRP, p. 451 472, 2000.

[3] P. Lambert and S. Régnier, "Surface and contact forces models within the framework of microassembly," Journal of Micromechatronics, vol. 3, pp. 123-157, 2006.

[4] A. Das, J. Sin, D. O. Popa, and H. E. Stephanou, "On the precision alignment and hybrid assembly aspects in manufacturing of a microspectrometer," in 4th IEEE Conference on Automation Science and Engineering, Aug. 2008, pp. 959 - 966.

[5] C. Clévy, A. Hubert, J. Agnus, and N. Chaillet, "A micromanipulation cell including a tool changer," Journal of Micromechanics and Microengineering, vol. 15, pp. 292-301, September 2005.

[6] J. Agnus, C. Clévy, Y. Urushima, R. Perez, A. Hubert, and N. Chaillet, "A micromanipulation station based on a new integrated microprehensile microrobot on chip (mmoc)," in 35th International symposium on robotics, Paris, France, March 2004.

[7] R. Perez, J. Agnus, C. Clévy, A. Hubert, and N. Chaillet, "Modelling, fabrication and validation of a high performance 2 dof microgripper," ASME/IEEE Transaction on Mechatronics, vol. 10, no. 2, pp. 161 - 171, April 2005.

[8] C. Clévy, A. . Hubert, and N. Chaillet, "Flexible micro-assembly system equiped with an automated tool changer," Journal of micro-nano mechatronics, vol. 4, pp. $59-72,2008$.

[9] Kuhnen and H. Janocha, "Complex hysteresis model of a broad class of hysteretic nonlinearities," in Conference on New Actuators, 2002.

[10] S. Devasia, E. Eleftheriou, and S. O. R. Moheimani, "A survey of control issues in nanopositioning," IEEE Trans. on Cont. Syst. Tech., vol. 15, pp. $802-823,2007$.

[11] J. S. H. Jung and D. Gweon, "New open-loop actuating method of piezoelectric actuators for removing hysteresis and creep," Review of Scientific Instruments, pp. 3436-3440, 2000.

[12] D. Croft, G. Shed, and S. Devasia, "Creep, hysteresis and vibration compensation for piezoactuators: atomic force microscopy application," ASME Journal of Dynamic Systems, Measurement and Control, vol. 123, pp. $35-44,2001$.

[13] M. Rakotondrabe, C. Clevy, and P. Lutz, "Hysteresis and vibration compensation in a nonlinear unimorph piezocantilever," in International Conference on Intelligent Robots and Systems, 2008, pp. 558 - 563.
[14] S. Haykin, Neural networks: a comprehensive foundation, P. Hall, Ed. Prentice Hall, 1998.

[15] S. Huang, K. K. Tan, and K. Z. Tang, Neural network control: theory and applications, R. S. Press, Ed. Research Studies Press, 2004.

[16] R. Selmic and F. Lewis, "Neural-network approximation of piecewise continuous functions:application to friction compensation," IEEE Transactions on Neural Networks, vol. 13, pp. 745 - 751, 2002.

[17] R. Murray, Z. Li, and S. Sastry, A Mathematical Introduction to Robotic Manipulation, CRC, Ed. CRC, 1994. 